\title{
DETERMINATION OF GROWTH AND AGE OF SLOW GROWING BRITTLE STARS (ECHINODERMATA: OPHIUROIDEA) FROM NATURAL GROWTH BANDS
}

\author{
CORINNA DAHM AND THOMAS BREY \\ Alfred Wegener Institute for Polar and Marine Research, PO 120161, D-27515 Bremerhaven, Germany. \\ E-mail: cdahm@awi-bremerhaven.de
}

\begin{abstract}
Growth in ophiuroids is highly variable, and with increasing size and age of an ophiuroid specimen more and more of the innermost growth rings on the vertebral ossicles become overgrown and hence invisible. Two approaches to estimate individual age of slow growing brittle stars using the high Antarctic species Ophionotus victoriae are compared. One method interprets natural growth ring readings as size-increment data, whereas the second method compensates for growth ring overgrowth by means of an iterative corrective approach. Preconditions as well as advantages and disadvantages of both methods are discussed.
\end{abstract}

\section{INTRODUCTION}

Ophiuroids contribute significantly to species diversity, abundance and biomass in many benthic communities (e.g. Hyman, 1955; Fell et al., 1969; Tyler, 1980; Barnes, 1987; Voß, 1988; Gerdes et al., 1992; Dahm, 1996). Individual growth and age are key parameters of population dynamics and are required to determine the significance of populations in the energy flow through an ecosystem.

Benthic organisms with calcareous shells or skeletal parts (e.g. corals, bryozoans, molluscs, echinoderms) can be aged either by mark-recapture techniques (for echinoderms e.g. Brey et al., 1995; Ebert, 1988; Steward, 1995; Medeiros-Bergen \& Ebert, 1995; Wilding \& Gage, 1995), or by interpreting natural growth bands patterns reflecting seasonal variations in skeletal growth. Until now, only a few attempts have been made to age ophiuroids by either technique (Gorzula, 1977; Gage, 1990a,b; Morison, 1979; Dahm, 1993, 1996; Medeiros-Bergen \& Ebert, 1995). Artificial markrecapture experiments have the advantage that growth can be directly related to time, whereas studies of natural growth band always imply that these bands are formed at regular (e.g. annual) intervals.

Growth bands of ophiuroids are produced by deposition of calcareous skeletal material with different density and/or structure. Environmental and internal factors such as temperature, food supply or reproduction can trigger changes in skeletal growth (Deutler, 1926; Ebert, 1968, 1988; Pearse \& Pearse, 1975; Smith, 1980; Gage \& Tyler, 1985; Gage, 1987; Dahm, 1993, 1996), but differences in food supply seem to be the most significant factor (Pearse \& Pearse, 1975; Jensen, $1969 \mathrm{~b})$. There is evidence that the rings observed in ophiuroid ossicles are laid 
down at regular, most likely annual, intervals in time, but there is still no direct proof for this assumption (Gorzula, 1977; Gage, 1990a,b; Morison, 1979; Dahm, 1993, 1996; Wilding \& Gage, 1995).

This study assumes that in the Antarctic species Ophionotus victoriae Bell, 1902 natural growth rings are formed annually and hence focuses on the question of how growth and age can be inferred from the number of growth rings visible on the vertebral ossicles.

\section{MATERIALS AND METHODS}

Two approaches to estimate growth and age of ophiuroids were compared. Method $A$ interprets natural growth ring readings as size-increment data, whereas method $B$ compensates for growth ring overgrowth by means of an iterative corrective approach. Both methods will be exemplified by the long living high Antarctic species Ophionotus victoriae which was collected during several expeditions to the southeastern Weddell Sea shelf (Dahm, 1996).

\section{Growth ring analysis}

Vertebral ossicles of ophiuroid arms consist of four wing-shaped fossae and a central articulating area (Figure 1). The ossicles are made up of a three-dimensional

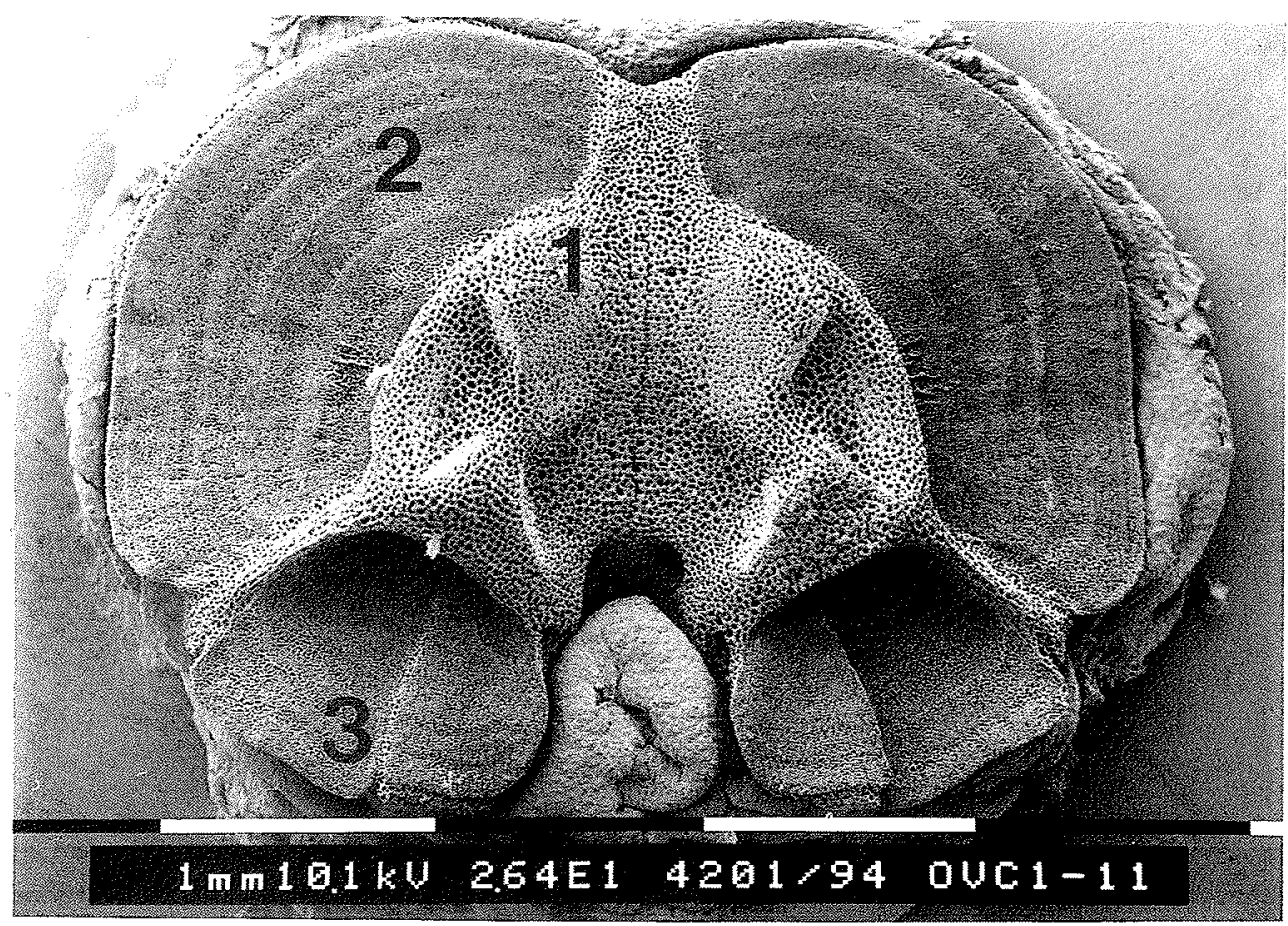

Figure 1. Ophionotus victorine: SEM photograph of a vertebral ossicle with growth bands on the fossae $(\times 26 \cdot 4)$. Disc diameter of the specimen: $22.2 \mathrm{~mm}$. 1, articulating area; 2 , upper fossa; 3 , lower fossa. Scale bars: $1 \mathrm{~mm}$. 
trabecular meshwork (stereom). The faces of the fossae exhibit a fine-textured labyrinthic stereom with a ring-like pattern in many species (e.g. Ubaghs, 1969; Smith, 1980; Bray, 1985) which is used for ageing (Gorzula, 1977; Morison, 1979; Gage, 1990a,b; Dahm, 1993, 1996). The stereom of the central articulating area is constructed of dense, high magnesium calcite and shows no banding patterns (see also Macurda, 1976; Gage, 1990a). For further details of skeletal anatomy and stereom micro structure see Wilkie (1978), Emson \& Wilkie (1980), Smith (1980), Wilkie \& Emson (1987), Gage (1990a), Dahm (1993).

Based on a method described by Gage $(1990 \mathrm{a}, \mathrm{b})$ the ossicles of 63 specimens were prepared and analysed by scanning electron microscopy (SEM). Ring measurements were made directly on SEM photographs. Growth rings on the ossicles were counted and measured on the aboral (upper) right fossa. For further details see Dahm (1993, 1996).

\section{Growth determination}

In echinoderms, individual growth is often found to follow a sigmoid pattern (e.g. Ebert \& Russell, 1992, 1993; Dahm, 1993, 1996; Brey et al., 1995). Therefore the Richards function to model individual growth was used:

$$
S_{t}=S_{\infty}\left(1-D \times e^{-K\left(t-t_{0}\right)}\right)^{\frac{1}{D}}
$$

where $S_{\infty}$ is asymptotic size, $K\left(\mathrm{y}^{-1}\right)$ is the growth constant, $\mathrm{D}$ is a shaping parameter and $t_{0}(y)$ determines the inflexion point of the curve.

\section{Method A - size-increment data (SID)}

The growth ring radius data $R_{X}$ of each individual are treated as size-increment data pairs (SID), i.e. radius $R_{t}$ at time $t$ and the next larger radius $R_{t+1}$ at time $t+1$. A rearranged form of the Richards function:

$$
R_{t+1}=\left(R_{\infty}^{D}\left(1-e^{K d t}\right)+R_{t}^{D}\left(e^{-K d t}\right)\right)^{\left(\frac{1}{D}\right)}
$$

is fitted to the pooled data from all specimens using the SIMPLEX algorithm (see Press et al., 1986). The parameter $t_{0}$ cannot be determined from SID, hence we use those small individuals in which the first and second growth ring are visible (see below) to estimate $t_{0}$ by:

$$
t_{0}=t-\ln \frac{1}{-K}\left(\frac{1}{D}\left(1-\frac{R_{t}}{R_{\infty}}\right)^{D}\right)
$$

\section{Method B - corrected size-at-age data (SAD)}

The massive articulating area and the fossae of the vertebral ossicles grow allometrically in diameter, i.e. with increasing size of the ossicle the articulating area will overgrow an increasing part of the fossae, thus hiding more and more of the innermost growth rings (Dahm, 1993). Only in very small juveniles are all growth rings visible. Cutting and grinding of the articulating area proved to be unsuitable to 


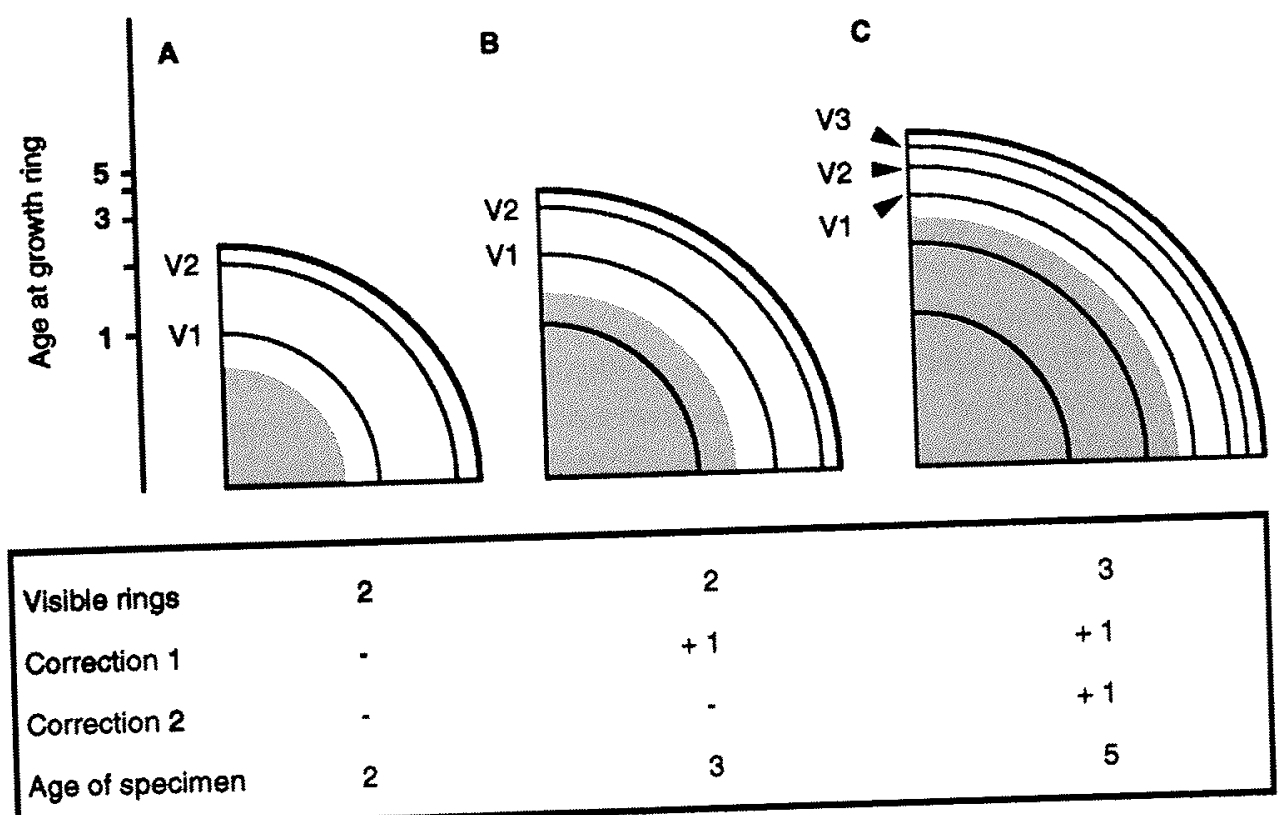

Figure 2. Schematic drawing of upper right fossae of vertebral ossicles of three different sized ophiuroid specimens: (A), small, 2-y old specimen, all rings visible; (B) 3-y old specimen, first ring overgrown by the articulating area; (C) 5 -y old specimen, first two rings overgrown by the articulating area. Stippled area, articulating area; V1, V2, V3, number of visible growth rings. Correction: number of each visible growth ring is increased by one (see text).

expose the hidden growth rings because it destroyed the delicate stereom structure. Hence, counts of visible growth rings underestimate the age of larger individuals (Gage, 1990a,b; Dahm, 1993, 1996) especially in slow growing and long living species, e.g. from the deep sea (Gage, 1990b) or from polar regions (Dahm, 1996).

Compensation for growth ring overgrowth was imposed by a refined and extended version of Dahm's (1993) method which has been applied previously to fast growing species only. The growth ring data are treated by an iterative corrective procedure according to the following protocol:

(1) on each ossicle all visible rings $V_{X}$ are sequentially numbered beginning with the innermost ring (Figure 2), and the radius $R_{X}$ is determined.

(2) Assumption that in the smallest specimens (disc diameter $<2 \mathrm{~mm}$ ) no growth rings are overgrown by the articulating area and hence the innermost visible ring corresponds to age 1 y (Figure 2A). These specimens are used to determine the maximum radius $R_{1 \text { max }}$ of the first ring.

(3) All remaining ossicles are checked to determine whether the radius of the innermost growth ring is above $R_{1 \max }$. If so, the number of each growth ring is increased by one (Figure $2 \mathrm{~B}, \mathrm{C}$ ). If not, the number of each growth ring corresponds to 'true' age $(\mathrm{y})$ and no further correction is necessary (Figure 2A). 


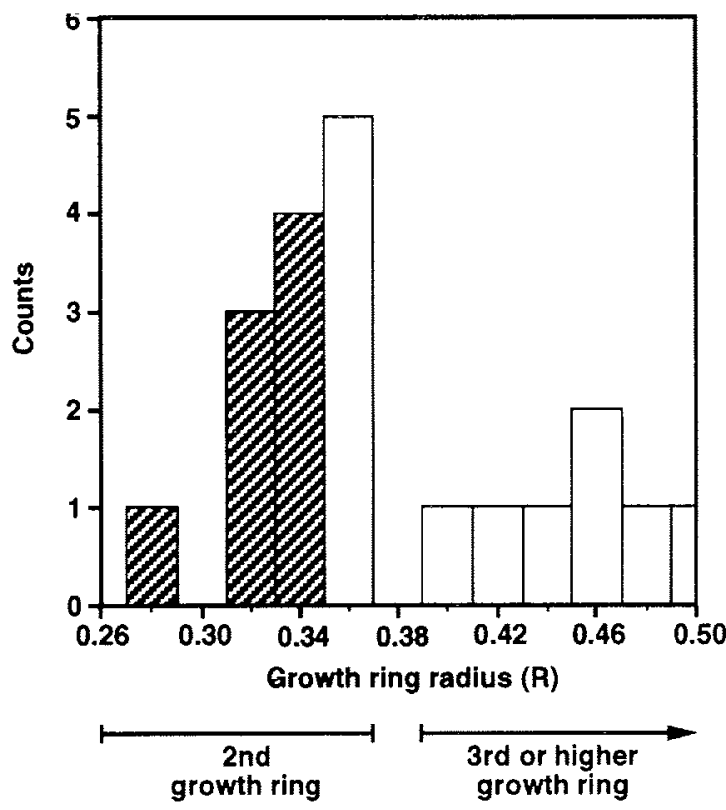

Figure 3. Radius frequency distribution of the innermost visible rings of those specimens used to determine $R_{2 \max }$. Dark bars: small specimens with all rings visible. The trough between 0.37 and $0.39 \mathrm{~mm}$ is interpreted as the border between the second and third ring and hence is used as $R_{2 \max }$.

(4) Those ossicles where growth ring numbers have been increased are then used to determine $R_{2 \text { max }}$. A radius frequency distribution of the innermost visible rings is checked for a trough, which should be equal to or above the largest already known $R_{2}$ and which is assumed to correspond to $R_{2 \max }$ (Figure 3 ).

(5) Steps (3) and (4) are iteratively repeated (Figure 2C) until no further ring number corrections are necessary, i.e. all ring numbers correspond to 'true' age.

The corrected growth band readings are treated as size-at-age data (SAD). The SIMPLEX algorithm (see Press et al., 1986) is used to fit the Richards function to the SAD:

$$
R_{t}=R_{\infty}\left(1-D \times e^{-K\left(t-t_{0}\right)}\right)^{\frac{1}{D}}
$$

\section{RESULTS}

Growth bands were counted in 63 specimens of Ophionotus victoriae. The distinctness of the growth marks in the ossicles varied little and ring readings of all specimens were included in the further analysis.

Figure 4 shows the relation between growth ring radius $R_{x}$ and number of visible growth rings $V_{X}$, i.e. prior to correction. This relation is described best by a linear regression:

$$
\mathrm{R}_{\mathrm{X}}=0.893+0.195 \mathrm{~V}_{\mathrm{X}}\left(\mathrm{N}=415(63 \text { specimens }) ; r^{2}=0.401 ; P<0.001\right) .
$$




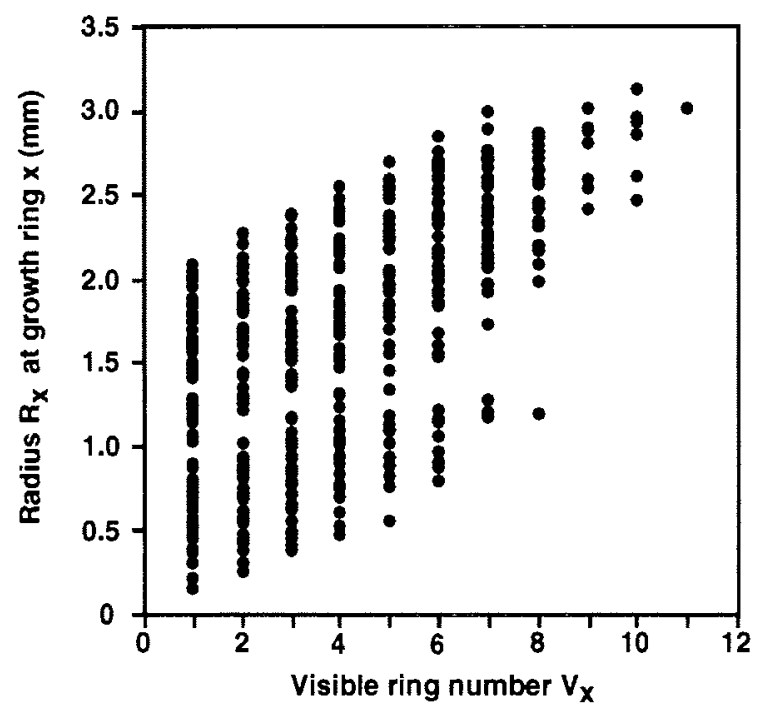

Figure 4. Relation between ring radius $R_{X}$ and the number of visible growth rings $V_{X} . N=415$ (63 specimens).

Method $A-$ size-increment data (SID)

The best fitting Richards function had the parameter values:

$$
\left.\mathrm{R}_{\infty}=3.42 \mathrm{~mm} ; \mathrm{D}=-1.143 ; \mathrm{K}=0.168(\mathrm{~N}=351 \text { (63 specimens }) ; r^{2}=0.955\right) \text {. }
$$

From the two individuals with first and second growth ring visible the computed age at inflexion point was $t_{0}=18 \cdot 86$. The corresponding growth curve is shown in Figure 5A.

\section{Method $B$ - corrected size-at-age data ( $S A D)$}

The correction procedure consisted of 12 iteratives (see Materials and Methods, steps 3 and 4), i.e. in larger specimens up to 12 rings were overgrown by the articulating area. The best fitting Richards model had the parameter values:

$$
\mathrm{R}_{\infty}=3.14 \mathrm{~mm} ; \mathrm{D}=-1.004 ; \mathrm{K}=0.248 ; \mathrm{t}_{0}=11.35\left(\mathrm{~N}=415 \text { (63 specimens); } r^{2}=0.955\right) \text {. }
$$

Figure 5A shows this growth curve compared to the one derived from SID. The disc diameter $\mathrm{D}$ is linearly related to ossicle size $\mathrm{R}$ (ring radius at the outer edge of the fossa) therefore $R_{\infty}=3.13 \mathrm{~mm}$ corresponds to $D_{\infty}=32.2 \mathrm{~mm}$ (Figure $5 B$ ). Based on this technique, the oldest specimen examined was $22-y$ old with a disc diameter of $32.5 \mathrm{~mm}$.

\section{DISCUSSION}

\section{Preconditions}

The applicability of both methods depends on several preconditions. As mentioned before, the basic question is whether changes in the stereom microstructure represent annual variability of growth or not. Compared to molluscs, there are relatively few 

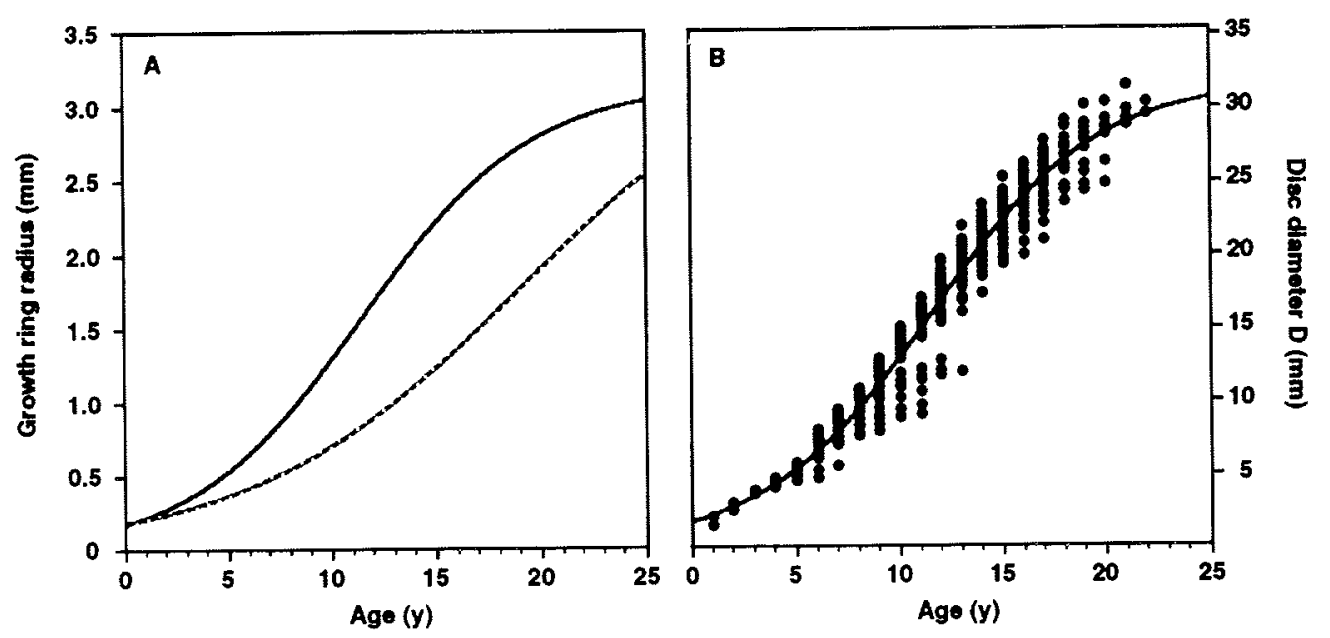

Figure 5. Richards growth curves fitted to size-increment data (SID) and to corrected size-at-age data (SAD). (A) Curves based on SID (stippled line) and SAD (solid line). (B) Curve based on SAD superimposed on SAD (dots). SID: $N=351$ (63 specimens); $R_{x}=3.42 \mathrm{~mm} ; \mathrm{D}=-1 \cdot 143 ; \mathrm{K}=0 \cdot 168$; $r^{2}=0.955$. $t_{0}=18.86$ computed from the two individuals with first and second growth ring visible. $\mathrm{SAD}: \mathrm{N}=415$ (63 specimens); $\mathrm{R}_{\infty}=3.14 \mathrm{~mm} ; \mathrm{D}=-1.004 ; \mathrm{K}=0.248 ; \mathrm{t}_{0}=11.35 ; r^{2}=0.955$.

studies dealing with growth bands in echinoderms (e.g. Deutler, 1926; Jensen, 1969a,b; Heatfield, 1971; Miller \& Mann, 1973; Pearse \& Pearse, 1975; Smith, 1980; Gage \& Tyler, 1985; Ebert, 1988; Dahm, 1993, 1996; Brey et al., 1995; Wilding \& Gage, 1995). For echinoids an annual rhythm of growth band formation could be demonstrated by controlled experiments in aquaria (Miller \& Mann, 1973) and by labelling experiments (Gage, 1992; Brey et al., 1995). For ophiuroids there is no proof available but several investigations suggest annual patterns in stereom growth to be due to seasonal environmental differences (Gage, 1990a,b; Dahm, 1993, 1996; Wilding \& Gage, 1995). Hence, it was assumed that growth rings formed annually in the high Antarctic species Ophionotus victoriae as found in the echinoid Sterechinus neumayeri from McMurdo Sound, Antarctica (Brey et al., 1995).

In order to infer age from SID (method A), at least one reliable estimate of size-atage is required, which is, in the case of the Richards model, used to compute $t_{0}$. The large difference between $t_{0}$ derived from the small individuals $(18.86 \mathrm{y})$ and $\mathrm{t}_{0}$ computed from SAD (11.35 y) leads to very different growth curves (Figure 5A) and hence age estimates. We believe the latter value of $t_{0}$ to be more reliable, because it is based on more data.

With regard to the corrective approach (method B), the starting point, i.e. the radius of the first (better the first and second) ring has to be known for a proper correction procedure. Therefore a sufficient number of juvenile specimens has to be available, which may be not the case here $(\mathrm{N}=2)$, because a trawl with $10-\mathrm{mm}$ mesh size was used for sampling. 


\section{Subjective interpretation of data}

All ring readings on ophiuroid ossicles such as described by Gage $(1990 \mathrm{a}, \mathrm{b})$ and Dahm $(1993,1996)$ suffer to a certain extent from subjective interpretation of ring patterns. Subjectivity could be reduced either by repeated analysis carried out by several independent investigators or by computerized analysis of digitized fossae pictures, similar to techniques applied to fish otolith reading (e.g. Troadec, 1991).

The iterative correction for overgrowth (method B) includes one more subjective step. In each iterative cycle, the maximum radius $R_{n}$ max (see Materials and Methods, step 4, Figure 3) is determined by the investigator. This is clearly the weak point of this approach, depending heavily on the number of specimens involved and the variability in ring diameter. A statistical analysis of the radius-frequency distribution would be a more objective procedure, but would require much more data (e.g. MacDonald \& Pitcher, 1979).

\section{Individual variability of growth}

Potentially high individual variability of growth, either genetically or environmentally induced, may be a common feature of echinoderm populations (Miller \& Mann, 1973; Gage, 1992; Ebert, 1988). This variability potentially affects the accuracy of any statistical analysis of growth data pooled from several species. Our experience with growth curve fitting, however, suggests that individual variability may introduce serious statistical artefacts in growth parameter estimates based on SID (method A). This topic has not yet been addressed systematically, but Figure 6 presents one example based on artificial data. The fit of the Richards model to
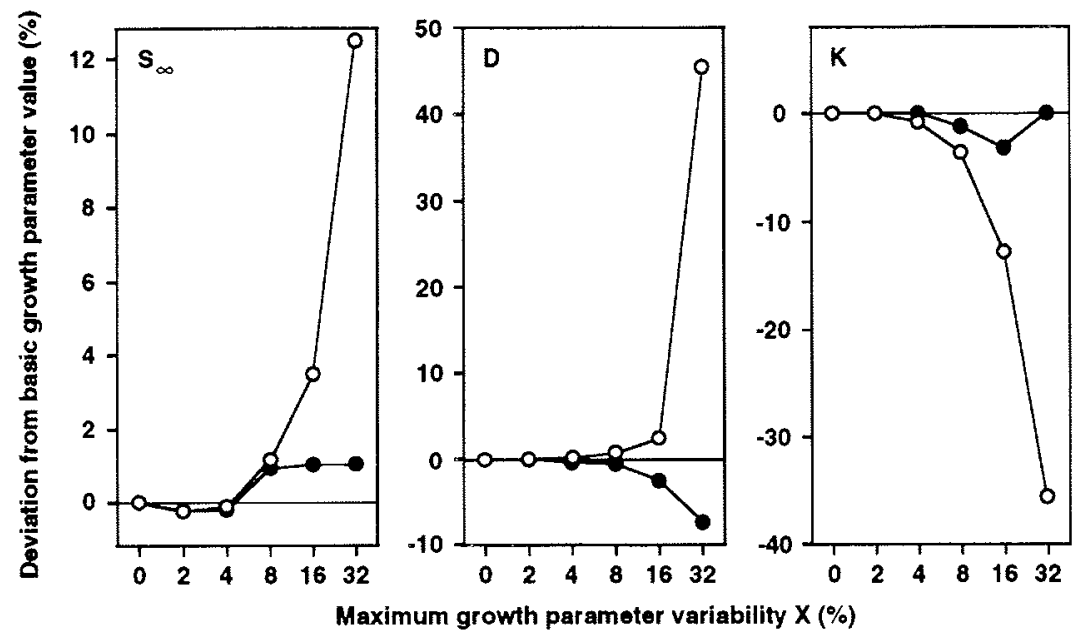

Figure 6. Parameters of Richards growth function fitted to artificial data with increasing individual growth parameter variability. Basic growth parameter values: $S_{\infty}=100 ; D=-0.50 ; K=0.25 ; t_{0}=10.00$. Variability function: basic parameter value $\pm x \%$ of parameter value, where $x=$ random number from interval $[-X,+X]$. For each value of $X$ ten individual parameter sets were randomly selected and the corresponding size-at-age $(0-24 \mathrm{y})$ determined. Richards functions were fitted to the data arranged as SAD and SID, respectively. The graphs show the deviation of the parameter estimates from the basic values. Circles, curve fit to SID; dots, curve fit to SAD. 
identical SAD and SID with an increasing level of growth variability among the individuals forming the population was compared. It is obvious from Figure 6 that increasing variability in growth leads to overestimation of the parameters $S_{\infty}$ and $D$, and to underestimation of the parameter $K$ when SID are used, whereas the picture is less obvious with respect to $S A D$. Hence the higher value of $S_{\infty}$ and the lower value of $\mathrm{K}$ derived with SID for $O$. victoriae (Figure 5) may be due to methodical bias.

The corrective procedure of method B will be affected by individual variability insofar as the maximum radius $R_{n \text { max }}$ (see Materials and Methods, step 4 ) is used to determine the upper limit of the radius of a certain growth ring. Hence, the resulting age estimates are biased towards the fast growing specimens. However, the alternative but more complicated application of a mean radius did not change our results distinctly.

Figure 5 indicates not only high individual variability of growth in Ophionotus victoriae, but also the possible existence of a subset of the population with slower growth between 5 and 15 years of age. We have no explanation for this phenomenon, but diseases or parasitism could be potential reasons for distinctly below-average growth in echinoderms (Jangoux, 1987a,b).

\section{Comparison of methods}

As discussed above, both approaches have some shortcomings. Estimating growth parameters from size-increment data (method A), however, has two major disadvantages: (i) the relation of the growth curve to the time axis is unknown as long as there is no reliable estimate of $t_{0}$ available. (ii) Depending on individual variability of growth, the growth parameter estimates may be biased seriously. The corrective approach to size-at-age data (method B) (i) requires more effort in data treatment and (ii) includes one more subjective step of analysis. Nevertheless, method $B$ is thought to be the more reliable way to estimate age and growth of slow growing ophiuroid species, especially when the natural growth rings have been proven to be formed annually by mark-recapture experiments. The corrective approach may used as a stand-alone method or in combination with advanced statistical procedures of size-frequency analysis such as described by Gage (1995).

C.D. was supported by a grant of the Deutsche Forschungsgemeinschaft (DFG). This is Alfred Wegener Institute Publication no. 1246.

\section{REFERENCES}

Barnes, R.D., 1987. Invertebrate zoology. Philadelphia: Saunders College Publications.

Bray, R.D., 1985. Stereom microstructure of the vertebral ossicles of the Caribbean ophiuroid Ophiocoma echinata. In Proceedings of the fifth International Coral Reef Congress, vol. 5 (ed. Antenne du Museum National d'Historie Naturelle, Committee on coral reefs), pp. 279-284. Moorea, Tahiti: Antenne Museum-EPHE.

Brey, T., Pearse, J., Basch, L., McClintock, J. \& Slattery, M., 1995. Growth and production of Sterechnius neumayeri (Echinoidea, Echinodermata) in McMurdo Sound, Antarctica. Marine Biology, 124, 279-292. 
Dahm, C., 1993. Growth, production and ecological significance of Ophiura albida and O. ophiura (Echinodermata: Ophiuroidea) in the German Bight. Marine Biology, 116, 431-437.

Dahm, C., 1996. Ökologie und Populationsdynamik antarktischer Ophiuroiden (Echinodermata). Berichte zur Polarforschung, 194, 1-289.

Deutler, F., 1926. Über das Wachstum des Seeigelskelets. Zoologische Jahrbiïcher, Abteiling Anatomie und Ontogenie der Tiere, 48, 119-200.

Ebert, T.A., 1968. Growth rates of the sea urchin Strongylocentrotus purpuratus related to food availability and spine abrasion. Ecology, 49, 1075-1091.

Ebert, T.A., 1988. Calibration of natural growth lines in ossicles of two sea urchins, Strongylocentrotus purpuratus and Echinometra mathaei, using tetracycline. In Echinodern biology (ed. R.D. Burke), pp. 435-443. Rotterdam: A.A. Balkema.

Ebert, T.A. \& Russell, M.P., 1992. Growth and mortality estimates for Red Sea urchin Strongylocentrotus franciscanus from San Nicolas Island, California. Marine Ecology Progress Series, 81, 31-41.

Ebert, T.A. \& Russell, M.P., 1993. Growth and mortality of subtidal Red Sea urchins (Strongylocentrotus franciscanus) at San Nicolas Island, California, USA: problems with models. Marine Biology, 117, 79-89.

Emson, R.H. \& Wilkie, I.C., 1980. Fission and autotomy in echinoderms. Oceanography and Marine Biology. Annual Review, 18, 155-250.

Fell, H.B., Holzinger, T. \& Sherraden, M., 1969. Ophiuroidea. Antarctic Map Folio Series, 11, $42-43$.

Gage, J.D., 1987. Growth of the deep-sea irregular sea urchins Echinosigra phiale and Hemiaster expergitus in the Rockall Trough (N.E. Atlantic). Marine Biology, 96, 19-30.

Gage, J.D., 1990a. Skeletal growth bands in brittle stars: microstructure and significance as age markers. Joumal of the Marine Biological Association of the United Kingdom, 70, 209-224.

Gage, J.D., 1990b. Skeletal growth markers in the deep-sea brittle stars Ophiura ljungmani and Ophiomusium lymani. Marine Biology, 104, 427-435.

Gage, J.D., 1992. Natural growth bands and growth variability in the sea urchin Echinus esculentus: results from tetracycline tagging. Marine Biology, 114, 607-616.

Gage, J.D., 1995. Demographic modelling in the analysis of population dynamics of deep-sea macrobenthos. Internationale Revue der Gesamten Hydrobiologie, 80, 171-185.

Gage, J.D. \& Tyler, P.A., 1985. Growth and recruitment of the deep-sea urchin Echinus affinis. Marine Biology, 90, 41-53.

Gerdes, D., Klages, M., Arntz, W.E., Herman, R.L., Galéron, J. \& Hain, S., 1992. Quantitative investigations on macrobenthos communities of the southeastern Weddell Sea shelf based on multibox corer samples. Polar Biology, 12, 291-301.

Gorzula, S.J., 1977. A study of growth in the brittle-star Ophiocomina nigra. Western Naturalist, 6, $13-33$.

Heatfield, B.M., 1971. Growth of the calcareous skeleton during regeneration of spines of the sea urchin Strongylocentrotus purpuratus (Stimpson); a light and scanning electron microscope study. Journal of Morphology, 134, 57-90.

Hyman, L.H., 1955. The invertebrates: Echinodermata. New York: McGraw-Hill.

Jangoux, M., 1987a. Diseases of Echinodermata. I. Agents microorganisms and protistants. Diseases of Aquatic Organsims, 2, 147-162.

Jangoux, M., 1987b. Diseases of Echinodermata. II. Agents metazoans (Mesozoa to Bryozoa). Diseases of Aquatic Organsims, 2, 205-234.

Jensen, M., 1969a. Age determination of echinoids. Sarsia, 37, 41-44.

Jensen, M., 1969b. Breeding and growth of Psammechinus miliaris (Gmelin). Ophelia, 7, 65-78.

MacDonald, P.D.M. \& Pitcher, T.J., 1979. Age-groups from size-frequency data: a versatile and efficient method of analyzing distribution mixtures. Journal of the Fisheries Research Board of Canada, 36, 987-1001.

Macurda, D.B., 1976. Skeletal modifications related to food capture and feeding behavior of the basketstar Astrophyton. Paleobiology, 2, 1-7. 
Medeiros-Bergen, D. \& Ebert, T.A., 1995. Growth, fecundity and mortality rates of two intertidal brittlestars (Echinodermata: Ophiuroidea) with contrasting modes of development. Joumal of Experimental Marine Biology and Ecology, 189, 47-64.

Miller, R.J. \& Mann, K.H., 1973. Ecological energetics of the seaweed zone in a marine bay on the Atlantic coast of Canada. III. Energy transformations by sea urchins. Marine Biology, 18, 99-114.

Morison, G.W., 1979. Studies on the ecology of the subantarctic ophituroid Ophionotus hexactis. MPhil thesis, University of London.

Pearse, J.S. \& Pearse, V.B., 1975. Growth zones in the echinoid skeleton. American Zoologist, 15, 731-753.

Press, W.H., Flannery, B.P., Teukolsky, S.A. \& Vetterling, W.T., 1986. Numerical recipes. The art of scientific computing. Cambridge: Cambridge University Press.

Smith, A.B., 1980. Stereom microstructure of the echinoid test. Special Papers on Palaeontology, 25, $1-81$.

Stewart, B., 1995. Use of the fluorescent marker calcein for biomineralisation studies of the snake star Astrobrachion constrictum (Echinodermata: Ophiuroidea). In Echinoderm research (ed. R. Emson et al.), pp. 277-282. Rotterdam: A.A. Balkema.

Troadec, H., 1991. Frequency demodulation on otolith numerical images for the automation of fish age estimation. Aquatic Living Resources, 4, 207-219.

Tyler, P.A., 1980. Deep-sea ophiuroids. Oceanography and Marine Biology. Annual Review, 18, $125-153$.

Ubaghs, G., 1969. General characteristics of the echinoderms. In Chemical zoology (ed. M. Florkin and B.T. Scheer), pp. 3-45. New York: Academic Press.

Voß, I., 1988. Zoogeographie und Gemeinschaftsanalyse des Makrozoobenthos des Weddellmeeres (Antarktis). Berichte zur Polarforschung, 45, 1-145.

Wilding, T.A. \& Gage, J.D., 1995. Skeletal growth marks in the brittlestar Ophiura ophiura (Linnaeus): do they reflect a seasonal growth pattern? In Echinoderm research (ed. R. Emson et al.), pp. 283-291. Rotterdam: A.A. Balkema.

Wilkie, I.C., 1978. Arm autotomy in brittlestars (Echinodermata: Ophiuroidea). Journal of Zoology, 186, 311-330.

Wilkie, I.C. \& Emson, R.H., 1987. The tendons of Ophiocomina nigra and their role in autotomy (Echinodermata, Ophiuroidea). Zoomorphology, 107, 33-44. 